\section{A light microscopic marker of non-A, non-B viral hepatitis}

As Grimaud and coworkers ${ }^{1}$ pointed out in their letter of 2 October 1980 , there is still a need for markers of non-A, non-B viral hepatitis. At present the diagnosis is made in those patients who present with histological and biochemical evidence of viral hepatitis, by exclusion of demonstrable HA, HB, cytomegalovirus or Epstein Barr virus infections. Electron microscopy may be of value ${ }^{2}$ but in routine diagnostic pathology, supplementary simple markers of non- $A$, non- $B$ viral infection would be welcome so long as specific serological tests are not available.

As part of a multidisciplinary study, we have made a morphological examination with light and electron microscopy of liver biopsies in five chimpanzees. Specimens were taken at weekly intervals after inoculation with non-A, non-B infectious material. In parallel a large number of liver biopsies, obtained from patients with presumptive non-A, non-B acute or chronic hepatitis were studied. We observed in liver biopsies of chimpanzees and humans a common striking histopathological feature. This consists characteristically of many small foci of single cell necrosis which resemble but are not identical to Councilman's bodies. The viral hepatocytotoxic effect produces small groups of irregular cell fragments localised in the space of Disse. These fragments are amphophilic and show coarse granularity (Fig. 1). Analogous

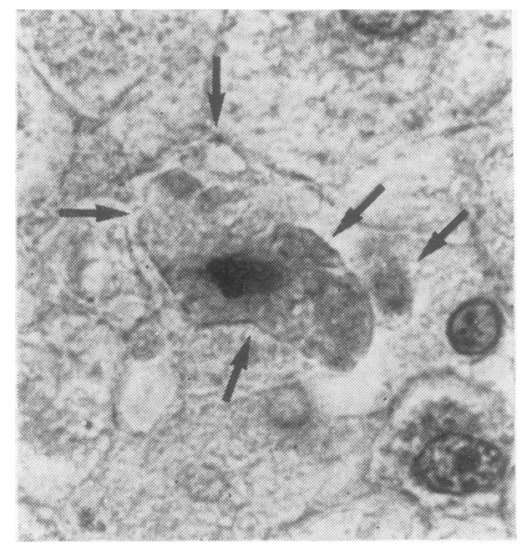

Fig. 1 Light microscopy. Fragmented Councilman-like body with coarse granularity $(\rightarrow)$ surrounded by unaltered hepatocytes in human liver biopsy.

Haematoxylin and eosin $\times 1600$. alterations can be recognised in the cytoplasm of some non-necrotic liver cells and transitional forms between this and the complete lesion may be found.

In tissue prepared for electron microscopy similar cell fragments may be identified. They are a mixture of membranous or microtubular structures or both surrounded by electron-dense flocculent material. In liver biopsies from chimpanzees a variable number of those cytoplasmic structures characteristic ${ }^{2}$ of non-A, non-B viral hepatitis, were found in addition in these fragments (Fig. 2).

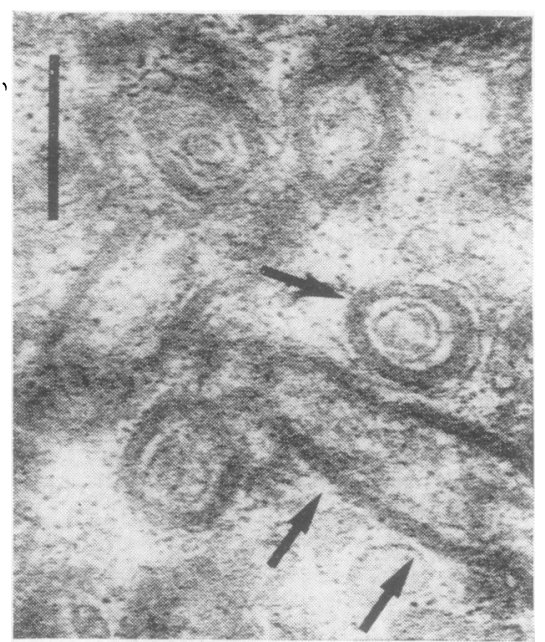

Fig. 2 Electron microscopy. Detail of a Councilman-like body showing disintegrating cytoplasmic structures $(\rightarrow)$ characteristic for non- $A$, non- $B$ hepatitis in chimpanzee liver biopsy. Scale marker denotes $0 \cdot 2 \mu \mathrm{m}$.

We suggest that the accumulations of fragmented "Councilman-like" bodies can be used as a light microscopic marker for the non-A, non-B viral aetiology of a hepatitis, just as groundglass hepatocytes may point to viral hepatitis type $\mathrm{B}$.

C DE WOLF-PEETERS R DE VOS VJ DESMET J FEVERY*

Departement Medische Navorsing, Academisch Ziekenhuis Sint Rafaël, Laboratorium voor Histochemie en Cytochemie,

*Laboratorium voor Hepatologie, Minderbroedersstraat 12, B-3000 Lewven, Belgium
References

${ }^{1}$ Grimaud J-A. Vitvitski L, Chevallier $\overrightarrow{\overrightarrow{\bar{S}}}$ Queron P, Trepo C. Hepatic intranuclear particles in patients with non-A, non- $\mathrm{B}$ C hepatitis. N Engl J Med 1980;303:818-9.흐

2 Shimizu YK. Feinstone SM. Purcell RH. Alter HJ, London WT. Non-A, non-B $\overrightarrow{\widetilde{\Phi}}$ hepatitis: ultrastructural evidence for two agents in experimentally infected chimpanzees. Science 1979;205:197-200.

Clinical significance of an ultrafast alkaline $\overrightarrow{\vec{\omega}}$ phosphatase isoenzyme

We have recently detected a technical़ error in our paper "Clinical significance of ${ }_{+}$ an ultrafast alkaline phosphatase iso- $-\mathrm{V}$ enzyme." 1 The error was in Fig. 11 ando random specimens Table 2 . It resulted $\overrightarrow{\vec{t}}$ from either an inadvertent misalignmento or a miscoring of the cellulose plate. The small band displaced anodally relative tothe ultrafast isoenzyme or band in the bottom tracing should coalign with the ultrafast band. Additionally, in Table $1 \overrightarrow{0}$ case 5 and 6 should have a positive signo in the ultrafast column corresponding to the tracings in Fig. 5 and Fig, 6.

Our initial preliminary observation on three random cases (retrospectively, all of which had evidence of liver disease) wereo based on the comparisons of densito-市 metric recordings. This was considered to be an objective means of assessingo differences in staining intensity rather than by subjective visual interpretation. However, when we recently assessed our originato experimental and control plate contain ing the random cases, by transillumin $\frac{?}{0}$ ation, although the plates had probablyo faded somewhat, we observed faint blue and/or blue-violet bands, and in most of the् terminal experimental band locations in the former, but not in the latter plate. Weo now appreciated a tinctoral difference in staining quality of some of these band when compared to the more cathodic. liver isoenzyme. This finding needs to beN further investigated. We have also occasionally seen this type of tinctorab coloration of the terminal region in some of our more recent studies.

In general we have tried to elucidate the terminal apparent isoenzyme of alkaline्ट phosphatase, and have found evidences which is suggestive of its presence on pro:longed comparing of subtle differences in the intensity of staining of the termina? anodal region between the experimentap and control plate. However we have found it difficult to reproduce our data consistently on repetitive testing of the 
same samples. This may be secondary to the lability of the diazonium staining reagent between the experimental and control plates that could randomly bias the results. We need to adopt a more sophisticated approach. An immunological technique, independent of enzymatic activity could be far more rewarding.

We would also like to clarify and amend our conclusion and summary. From our original random cases we determined that the ultrafast isoenzyme may be a true isoenzyme. However, it was the band in the ultrafast region seen on electrophoresis which may or may not have indicated the presence of a true isoenzyme and at times it appeared to be an artefact that we observed most commonly in our limited study associated with neoplastic liver disease.

In conclusion, we are not sure of the definite existence of an ultrafast isoenzyme although we have demonstrated suggestive evidence of its existence on a number of occasions. It has remained elusive despite our attempts to study it further. It may be that bilirubin effectively competes for the diazonium reagent thereby preventing detectable expression of enzymatic activity, especially when only small quantities of enzyme may be released in patients with liver disease. Additionally, small quantities of enzyme might not be detected secondary to the intensity of the non-enzymatic reaction. We feel that the ultrafast band is non-specific in that it may be seen in patients with benign and malignant liver disease and may well be artefactual as
Hardin's study suggested. At this time no 岂 definitive association between the ultrafast 은 band and a specific disease entity can be $\overrightarrow{\vec{A}}$ made.

J KOETT 으

PL, WOLF 음

Department of Pathology, $\frac{\bar{\sigma}}{\bar{D}}$ University of California Medical Center, San Diego University Hospital, San Diego, क California 92103, USA $\overrightarrow{0}$

Reference

${ }^{1}$ Koett J, Wolf PL. Clinical significance of an $\vec{\omega}$ ultrafast alkaline phosphatase isoenzyme. Oे $J$ Clin Pathol 1979;32:1286-92.

The opinions or assertions herein are the private views of the authors and are not to be $\stackrel{\omega}{\perp}$ construed as official or as reflecting the views of the US Department of Defense or the $\infty$ Department of the Navy.

\section{Book reviews}

Histological Typing of Prostate Tumours. International histslogical classification of tumours. No 22. Ed FK Mostofi. (Pp 25; 64 colour photomicrographs; Sw Fr 109.) WHO Geneva. 1980.

The most useful part of this book is the Introduction where carcinoma of the prostate is identified as (a) clinical, (b) occult, and (c) incidental (subclinical). It would be helpful if some such standard classification were employed. However, latent carcinoma-a popular term in Britain-is mentioned only in passing as applying to cancers found at autopsy. This is perverse and illogical and may undermine the credibility of the proposals. The more detailed histological classification and the accompanying photomicrographs are not very helpful and in particular offer no help in that common diagnostic dilemma the 'incidental' (?'Iatent') carcinoma.

The illustrations are classical examples of recognised conditions and contribute little to the standardisation of nomenclature which is the object of these publications. I think this is one of the less valuable volumes in this series.

HM CAMERON

Haemophili in Medical Literature. DC Turk. (Pp 96; £6.50.) Hodder \& Stoughton. 1980.

This bibliography on the haemophili consists of a list of books and review articles with an indication of their contents followed by a list of more than 1200 references, largely recent but ranging from 1883 to 1978 . Even more valuable is an index clearly and minutely categorising the references into 37 subject headings and numerous sub groups. The instructions on the use of the index are readily mastered. This most useful piece of scholarship must be of the greatest value to those working with the haemophili.

GL GIBSON

Virus and the Liver. Eds L Bianchi, W Gerok, K Sickinger, GA Stalder. (Pp 424; illustrated; £24.95.) MTP Press Limited. 1980.

The proceedings and discussions during the three days of the 5th International Congress of Liver Diseases in October, 1979, give a detailed picture of the state of knowledge at that time. It is well presented and well edited, containing much which is stimulating. The coverage is broad, with more attention to the liver, to pathogenetic, clinical, and epidemiological aspects than to the viruses as such although these are well and concisely dealt with. The sessions dealt respectively with virology, viral and host antigens, pathology and immunology, clinical pathology and epidemiology (with a salutary reminder that fulminating hepatitis, from which deaths in the acute stage result, affects only $1 / 1000$ patients with acute viral hepatitis irrespective of whether due to hepatitis A, B or "non-A non-B"). The last session dealt with therapy (preventing or treating complications

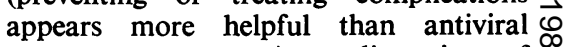
measures at present), a discussion of $\stackrel{\infty}{-}$ prophylaxis and the possible role of vaccines against hepatitis $B$, and lastly a fine summary by Dame Sheila Sherlock followed by the latest hepatitic poem by HJ Alter. Each session contains from four to ten papers, discussions are effectively $\stackrel{\square}{\square}$ recorded, and useful summaries with $\overrightarrow{\vec{A}}$ wise comments conclude the sessions. In $\frac{0}{3}$ such a rapidly evolving field symposium proceedings are inevitably of ephemeral value but this is certainly one of the better ones and contains information fully 웅 commensurate with its price.

NR GRIST 을

Malignant Lymphoproliferative Diseases. Ed JG van den Tweel. (Pp 507; illustrated; 145 guilders.) Martinus Nighoff. 1980.

Malignant Lymphoproliferative Diseases is a compilation of papers presented at a Boerhaave course organised by the Uni- of versity of Leiden, Holland, early in $1979 . N$ The justification for books of this kind lies in the presentation of new material from a number of well established experts in the field in a readable and convenient format. In these interests, poor printing and editorial lapses which characterise this type of publication can often be excused but this book is appearing almost two years after the course with the result that much of the material is no longer new and much that is of current interest, for example, the application of monoclona

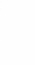

